\title{
$\$$ sciendo \\ METHODS OF ENERGY EFFICIENCY IMPROVEMENT BY MODERNISATION OF HYDRAULIC INSTALLATIONS AT A FISHING CUTTER AT THE BALTIC SEA
}

DOI 10.2478/ntpe-2018-0070

\author{
Dr. Eng. Marcin Szczepanek \\ Dr. Eng. Przemysław Rajewski \\ Maritime University of Szczecin, Poland \\ Doc. Ing. Dalibor Barta, PhD. \\ University of Žilina, Slovak Republic \\ Assoc. Prof. Iwona Michalska-Pożoga \\ Technical University of Koszalin, Poland
}

\begin{abstract}
The Energy Efficiency Design Index (EEDI) became mandatory for new ships as well as the Ship Energy Efficiency Management Plan (SEEMP) for all ships due to the MEPC 62 (July 2011) along with the adoption of amendments to MARPOL Annex VI by the Parties to the MARPOL Annex VI. This was the first legally binding climate change treaty to be adopted since the Kyoto Protocol. The Ship Energy Efficiency Management Plan (SEEMP), which has been obligatory since 2013, did not to cover fishing cutters but triggered the implementation of energy efficiency audits due to fishing limits, high fuel prices, and free freight market. All the above caused that ship-owners started seeking ways for saving money and keep their business profitable. Apart from energy recovery installations, fishing vessels have been furnished with the latest technologies aimed at the reduction of energy consumption and at making ships greener. A research team of the Maritime University of Szczecin conducted energy efficiency audits on several fishing vessels operated on the Baltic Sea and stated that up to $40 \%$ of the energy is used during fishing operations by hydraulic devices installed at the fishing vessels. The paper presents the measurement results of energy consumption in typical operational states based on a selected fishing cutter operating at the Baltic Sea. The paper includes also the recommendations in terms modernization of hydraulic installations and the changes of control methods for devices with hydraulic drive. The calculations are also presented herein and they prove that it is possible to reduce energy consumption by a fishing cutter even by $20 \%$ while maintaining the unchanged operating parameters of the hydraulic devices.
\end{abstract}

Keywords: fishing cutters, hydraulic installations, energy efficiency

\section{INTRODUCTION}

The development of an energy audit programme, dedicated for this specific vessels' group, aims at the improvement of energy efficiency for fishing vessels' operation by presenting to fishermen solutions reducing energy input while operating vessels. Shipowners, depending on their financial capability and investment policy, may select the simplest, operational solutions that do not require funding or more complex solutions requiring significant financial resources, but also considerably improving the vessels' energy efficiency. The first step towards adopting an exercise in energy efficiency on ships and to harvest the resultant savings is an energy audit. Energy audit basically consists of identifying core areas where conservation of energy can be done and then developing a programme for the same. The objectives of conducting an energy audit are as follows:

- to identify areas where there is a loss of energy due to reduced efficiency or incorrect operation, and cost savings resulting from having them corrected.

- to identify areas where new developed technology may reduce cost.

- to project the information without omitting anyone, to the buyer so that he can make a decision based on cost and profit. 
- to improve the energy efficiency of the ship by saving fuel and also to reduce global warming by emission control and help go green.

A general overview of the energy audit process on ships is conducted in the following steps:

- data collection: All relevant data for the applicable machine is collected. The data may be collected from mechanical means such as counters, running hour indicators, event logs etc. In case these are not available, the duty engineers and operators are interviewed.

- condition evaluation: The condition of the machinery is evaluated and it is determined whether any overhaul or components replacement may improve its performance.

- economic alternatives: The audit will also provide an information to the owner about the economic alternatives available and will be helpful to make a decision.

- audit report: Finally, the energy audit report is created.

The assessment and the comparison of energy efficiency in different economy sectors play an increasingly important role in internal and international policies of most countries (IMO 2009, Matuszak et al. 2014). This is due to the desire to increase the level of economy competitiveness, to ensure country energy security and to the improve green image and obtain benefits resulting from the reduction of carbon dioxide. The intention and efforts to reduce the volume of fuel consumed by the Polish fishing vessels contributed to perform energy audits by the scientists of the Maritime University of Szczecin. The research results' analysis of the operational power systems of the Polish fishing fleet (Behrendt C. 2014) allowed for an assessment of energy consumption for particular energy receivers (with respect to $100 \%$ chemical energy in fuel) (Fig. 1) (Notti et al. 2012, Schau et al. 2009):

- main drive $60-75 \%$,

- fishing gear (hydraulic drive) 10-15\% (Schau et al. 2009, Parente et al. 2008),

- electrical equipment $2-15 \%$.

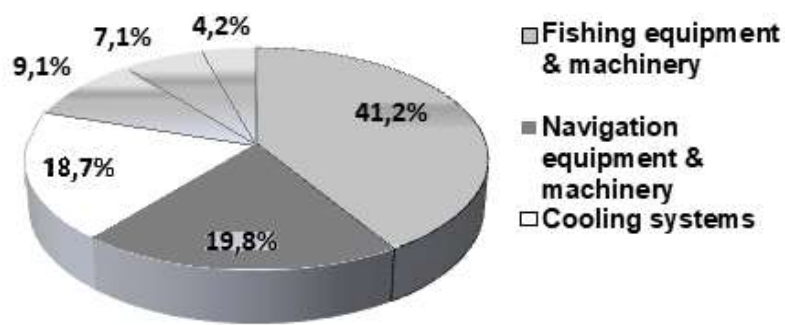

Fig. 1. Energy consumption scheme on cutter KO $\measuredangle 206$ during fishing operations. Source: own elaboration

During fishing operations, hydraulic devices consume even up to $40 \%$ of the energy generated on a ship (Behrendt C. 2014, Basurko et al. 2013). Given the above analysis of the demand on energy at fishing vessels, it shall be concluded that the intention to reduce energy consumption and $\mathrm{EEOI}_{F}$ factor should not focus only on main drive systems since the energy loss in hydraulic installations may result in the fuel reduction up to $14 \%$. The major number of working machinery and equipment on fishing vessels are equipped with devices with hydraulic as they are user-friendly, easily serviceable, and reliable. On fishing cutters, energy for hydraulic devices is commonly provided by hydraulic oils pumped by the pumps driven directly from the main engine transmission gear, and less frequently by electric motors.

\section{ANALYSIS OF THE METHODS TO REDUCE ENERGY CONSUMED BY HYDRAULIC FISHING EQUIPMENT}

The scope of research performed by the team of Maritime University of Szczecin included an analysis of the options and methods enabling the improvement of operational efficiency of fishing vessels by the reduction of energy consumed by the working hydraulic equipment. This solution may result in lower operational costs and limited $\mathrm{CO}_{2}$ emission. The analysis was based on the research results and the measurements carried out at two B 280 fishing cutters, marked as KOŁ 206 and KOŁ 6 (Fig. 2). Both vessels are equipped with developed hydraulic power systems. The systems are used to drive fishing and reloading equipment and machinery 
and to provide power to the propulsion system. The vessel is propelled by the $\mathrm{H}$. CegielskiSulzer 6AL20/24 engine with $420 \mathrm{~kW}$ at $750 \mathrm{rpm}$ with the Zamech ACG 450 singletransmission gear. The engine installed at the front drives the mechanical gear which drives two 3-section gear pumps, and 50kW power generators. The controllable pitch propeller is driven by the propeller shaft coupled with the driving shaft. Additionally, the engine room is equipped with $41.6 \mathrm{~kW}$ internal combustion engine, Andrychów SW400. On the main deck, in the stern area on the starboard side, a power generator - John Deere 668FM - is mounted. It generates power fed to the ship-based fish processing plant. The hydraulic pumps provide power to two trawl winches, two net winches, and 2 auxiliary winches. A simplified scheme is presented in Figure 3.

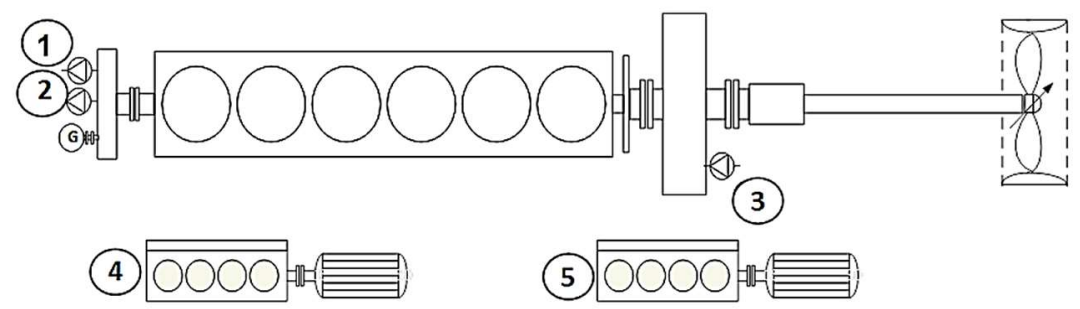

Fig. 2. Propulsion system and power system at KOŁ 206:

1 and 2 - hydraulic pumps for deck equipment, 3 - hydraulic pumps for gear, 4 - power generator ZE400/54, 5 - John Deer power generator unit for RSW units Source: own elaboration

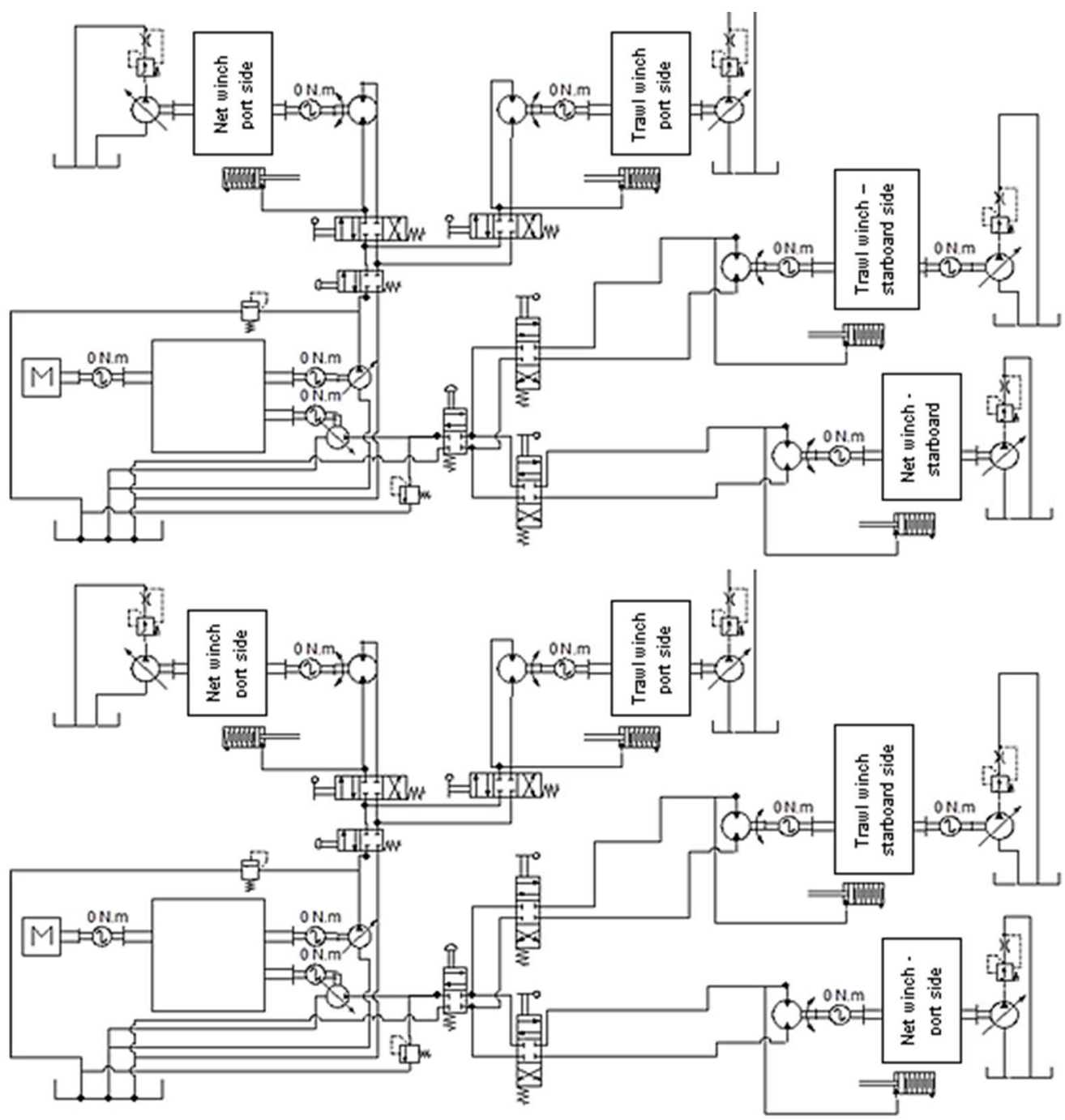

Source: own elaboration

Fig. 3. Hydraulic power system on KOŁ 206 
Hydraulic cylinders are driven by hydraulic oil pumped by two 3-section gear pumps, Waryński 32100. Their capacity equals to $3 \times 70,5 \mathrm{ml} /$ rotation at $16001 / \mathrm{min}$ and at 160 bar operating pressure. The pumps are non-disengagebly driven by the main engine gear. Fishing cutters are equipped with two identical trawl winches of WTJ-25h-2 type. One winch is mounted in the port side and the second one on the starboard side. Their nominal towing power equals to $=2.5 \mathrm{~T}$ due to the hydraulic motor SOK $630 \mathrm{k} 72$. The engine' parameters are as follows: torque $-6.3 \mathrm{kNm}$, operating pressure $-160 \mathrm{bar}$, maximum rotational speed $-1601 / \mathrm{min}$ and nominal power $-68 \mathrm{~kW}$. There are also two net winches installed, driven by SOK 1000 engines, and two auxiliary winches. The latter ones are used for unloading trawl net and for other, supporting operations. They are driven by SOK 630 motors (Behrendt, 2014). Figure 4 presents the distribution of the net winches on KO 2 206. Approximate operating times of fishing gear are as follows:

- trawl net laying out - operating time for the net winch and two trawl winches around $30 \mathrm{~min}$;

- trawl pulling - operating time for two trawl winches - around 30 min;

- trawl net pulling - operating time for the net winch - around $30 \mathrm{~min}$.

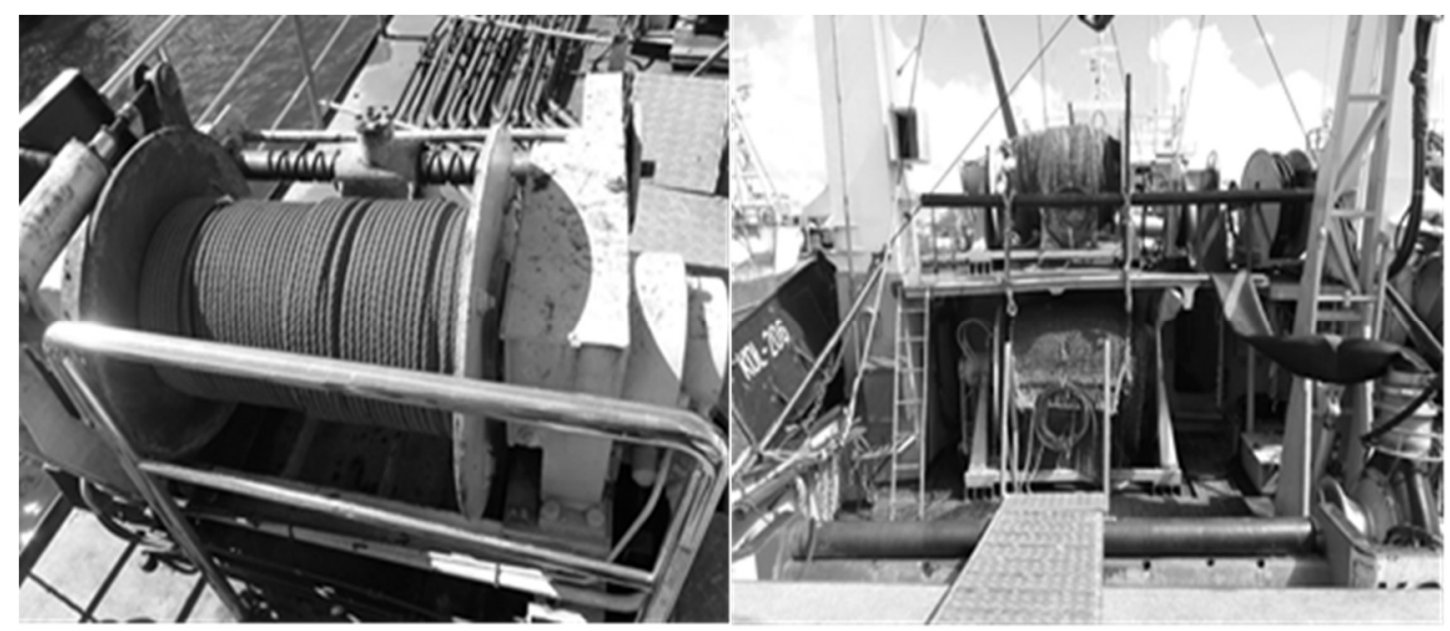

Fig. 4. Trawl winch (on the left) and net winches (on the right) on KOŁ 206.

Source: own elaboration.

Within 24 hours, 3-4 fishing operations are carried out. During catching fish, the researchers performed a number of measurement on both vessels. They measured the volume of power consumed by the hydraulic pumps and loads of deck winches during fishing operations.

Low performance of the system and a significant amount of power consumed by the pumps, being in operation during travelling to the fishery and back to the port, proved that it is necessary to seek for solutions aimed at the improvement of the energy efficiency for that section of fishing cutters.

The authors analyzed two structural changes in terms of options allowing to save fuel and to specify benefits that might be obtained if:

- multi-piston pumps are installed as a part of a hydraulic power system;

- hydrokinetic couplings are mounted.

It was calculated that if 3-section gear pumps are replaced by multi-piston pumps, then the power required to drive them is significantly lower (Thanasansakorn and Manomayidthikarn, 2015, Behrendt, 2014) The calculation results are presented in Figure 5 and Figure 6. 


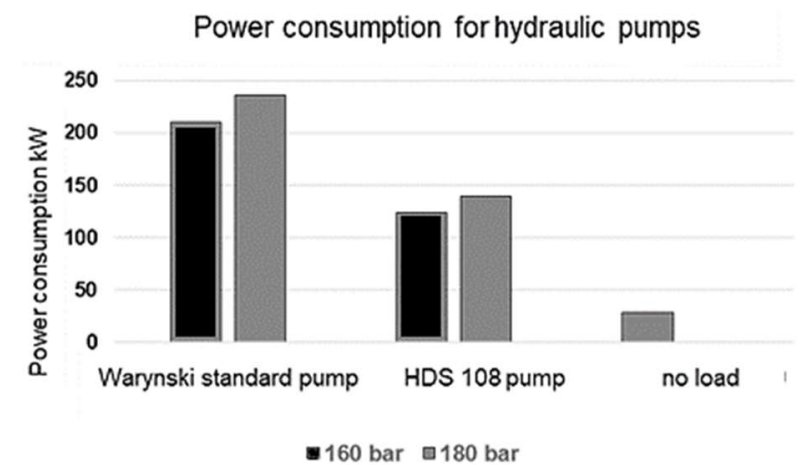

Fig. 5. Power consumed by hydraulic pumps at operating pressure of $160 \mathrm{bar}$ and maximum pressure of 180 bar.

Source: own elaboration

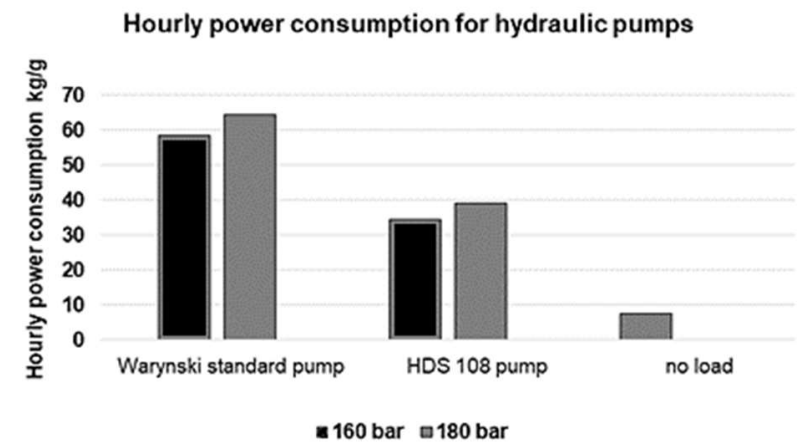

Fig. 6. Hourly power consumption for the existing and proposed hydraulic pumps Source: own elaboration of KO $\longleftarrow 206$ at the pressure of 160 bar and 180 bar.

The following analysis stage covered the matter of the purposefulness of using remotely controlled disengaging couplings. When pumps operate without load, the hydraulic oil circulates in "short circulation" (tank - pump - tank). However, the amount of power consumed is significant and is in the range from $4 \%$ to $10 \%$ of the nominal power subject to the oil temperature. In order to perform calculations, the value of $5 \%$ was adopted (Szczepanek M 2015). The disconnecting couplings enable for disengaging pumps' drive at idle without any load, and therefore it results in the reduced fuel consumption.

\section{CONCLUSION}

The use of multi-piston pumps, HDS 108, of higher general capacity instead of gear pumps results in much lower power consumption and hourly fuel consumption. In relation to the hydraulic motors, the power volume consumed by piston pumps is $41 \%$ lower than by the gear pumps installed at the vessel subject to the research. It results in $24 \mathrm{~kg} / \mathrm{h}$ less fuel consumed by the main engine. Assuming that the hydraulic pumps are operated $6 \mathrm{~h}$ per a working day, it shall mean that $140 \mathrm{~kg}$ of fuel is saved. The cost of one HDS 108 pump equals to EUR720.

By disengaging the hydraulic pumps' drive by electromagnetic coupling when they are not required to operate, it is possible to save $7.78 \mathrm{~kg} / \mathrm{h}$ of fuel.

Assuming that the pumps are operating when the trawl and the net are laid out, the operation time during one fishing operation is as follows:

- trawl net laying out - operating time for the net winch and two trawl winches around $30 \mathrm{~min}$;

- trawl pulling - operating time for two trawl winches - around 30 min;

- trawl net pulling - operating time for the net winch - around $30 \mathrm{~min}$.

With 3-4 fishing operations per day, the pumps operate under a load for 6 hours, while during the remaining 18 hours the operations are performed at the idle. During that time the amount of fuel that might be saved equals to $140 \mathrm{~kg}$. When considering the above and the price of MGO fuel at the level of EUR 670 per a tonne, daily savings, being the result of the reduced 
fuel consumption, would amount to EUR98. Given the above and the purchase cost including installation services for a coupling equaled to EUR20,000, the investment shall return in two years if fishing operations are performed 100 days per year.

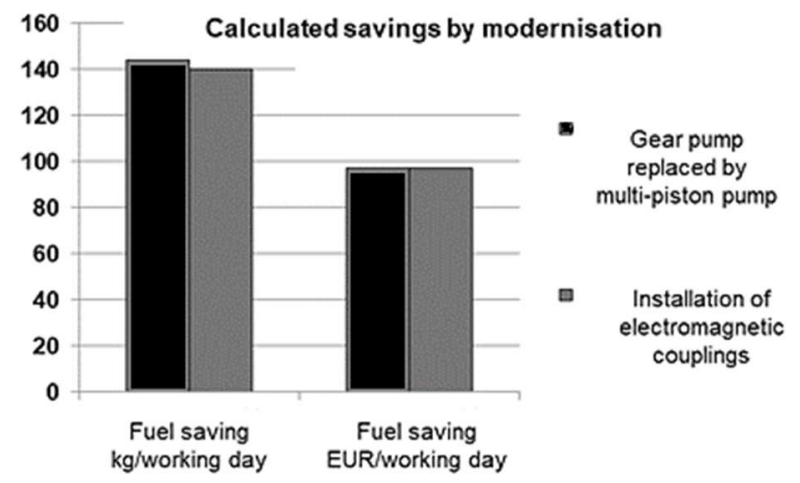

Fig. 7. Calculated savings in terms of fuel consumption after modernization.

Source: own elaboration

The modernisation of the hydraulic system on KOŁ 206 may result in the substantial reduction of consumed fuel, improve the energy efficiency and reduce the operational costs. Due to mounting piston pumps, the fuel savings are comparable to the savings obtained when couplings disengaging the drive for the hydraulic pumps are installed. The cost of replacement of gear pumps with multi-piston pumps is much lower than the cost of assembly of an electromagnetic coupling, and the savings for both solutions are comparable. If both solutions are applied, the power and fuel consumption may be reduced significantly and their added cost of investment might return even after one year if the vessel is fully and actively operated.

\section{ACKNOWLEDGEMENTS}

This research outcome has been achieved under the research project no. 2/S/IESO/2018 financed from a subsidy of the Polish Ministry of Science and Higher Educations for statutory activities of Maritime University of Szczecin.

\section{REFERENCES}

Basurko, OC. Gabina, G. Uriondo, Z. (2013). Energy performance of fishing vessels and potential savings, Journal of Cleaner Production, Vol: 54 , pp. 30-40

Behrendt C. (2014). Energy saving technologies for fishing vessels, Scientific Journals of the Maritime University of Szczecin, Vol. 39,Issue: 111, pp 11-15

Gaffney M.(2016). Green boats and ports for blue waters. University of Rhode Island, April 5, 2016.

IMO (2009). Guidance for the development of a Ship Efficiency Management Plan. MEPC.1/Circ. 683, London.

Matuszak Z., Nicewicz G., Szczepanek M.(2014). Podstawy audytu energetycznego statku rybackiego. Materiały konferencji DIAGO Ostrawa, pp.162-167.

Notti E., Buglioni G., Sala A. (2012). An energy audit tool for increasing fishing efficiency, International Symposium on Fishing Vessel Energy Efficiency, E-Fishing, Vigo, Spain,

Parente J., Fonseca P., Henriques V., Campos A. (2008). Strategies for improving fuel efficiency in the Portuguese trawl fishery. Fisheries Research 93, pp.117-124

Schau E. M., Ellingsen H., Endal A, Aanondsen S. A (2009). Energy consumption in the Norwegian fisheries. Journal of Cleaner Production 17, pp.325-334

Szczepanek M.(2015). Factors affecting the energy efficiency of fishing vessels, Scientific Journals of the Maritime University of Szczecin, Vol. 42 Issue: 114, pp 38-42

Thanasansakorn S., Manomayidthikarn K (2015). Hauling device and hydraulic engineering for fishing boats. Available at http://map.seafdec.org/downloads/pdf/Fishery20Equipment20and20hydraulic20engineer. pdf [Accessed 16 May. 2018]. 